\title{
Variability and Pattern of Spontaneous Respiration in Different Types of Cardiac Rhythm Regulation of Highly Trained Athletes
}

\author{
Alexander Romanchuk ${ }^{1, *}$, Oksana Guzii ${ }^{2}$ \\ ${ }^{1}$ Department of Physical Therapy and Occupational Therapy, Lviv State University of Physical Culture named after Ivan Boberskiy, \\ 79007, Lviv, Ukraine \\ ${ }^{2}$ Department of Human Health and Sports Medicine, Lviv State University of Physical Culture named after Ivan Boberskiy, 79007, \\ Lviv, Ukraine
}

Received October 30, 2020; Revised November 24, 2020; Accepted December 30, 2020

\section{Cite This Paper in the following Citation Styles}

(a): [1] Alexander Romanchuk, Oksana Guzii , "Variability and Pattern of Spontaneous Respiration in Different Types of Cardiac Rhythm Regulation of Highly Trained Athletes," International Journal of Human Movement and Sports Sciences, Vol. 8, No. 6, pp. 483 - 493, 2020. DOI: 10.13189/saj.2020.080622.

(b): Alexander Romanchuk, Oksana Guzii (2020). Variability and Pattern of Spontaneous Respiration in Different Types of Cardiac Rhythm Regulation of Highly Trained Athletes. International Journal of Human Movement and Sports Sciences, 8(6), 483 - 493. DOI: 10.13189/saj.2020.080622.

Copyright $\odot 2020$ by authors, all rights reserved. Authors agree that this article remains permanently open access under the terms of the Creative Commons Attribution License 4.0 International License

\begin{abstract}
Using spiroarteriocardiorhythmography, 202 highly qualified male athletes aged $22.6 \pm 2.8$ years, who are representatives of acyclic sports were examined. According to HRV (hearth rate variability), the types of the athletes' cardiac rhythm regulation were determined. There are 4 types of autonomic regulation of cardiac rhythm: Type I - indicates moderate stress, Type II - indicates a decrease in the functional state of regulatory systems, the development of fatigue, Type III - indicates the optimal state of regulation, Type IV - indicates overstrain of autonomic regulation or high fitness. The athletes with a predominance of central (types I and II) and autonomous (types III and IV) effects on the cardiac rhythm regulation are differentiated by indicators of total respiration power $\left(\mathrm{TP}_{\mathrm{R}},(\mathrm{l} / \mathrm{min})^{2}\right)$ and power in the high frequency range $\left.\left(\mathrm{HF}_{\mathrm{R}}\right),(\mathrm{l} / \mathrm{min})^{2}\right)$. Athletes with the type IV cardiac rhythm regulation had a more significant contribution of the low-frequency component $\left(\mathrm{LF}_{\mathrm{R}} \mathrm{n}\right.$, n.u.) in the regulation of spontaneous respiration than athletes with type I and II cardiac rhythm regulation. In the type II regulation of cardiac rhythm there is a significant decrease in expiratory duration (s), which is also manifested by a significant increase in the ratio of inspiratory and expiratory phases, which may characterize expiratory insufficiency for this type.
\end{abstract}

Keywords Spiroarteriocardiorhythmography, HRV, Types of Autonomic Regulation of Cardiac Rhythm, Respiration Variability, Respiration Pattern

\section{Introduction}

An important component of medical control over athletes within the training process is to determine the body's functional reserves for targeted training process [1-7], as well as the establishment of systems that limit the possibility of training [8-13] and under certain conditions can lead to pre-pathological and pathological conditions connected with stress and failure of adaptation mechanisms [14-23]. This circumstance requires the use of modern integrative methods of functional study of the organism in the "field conditions" [24-29]. The latter requires the development of informative functional criteria that could not only differentiate pre-pathological conditions [1,2,10,11,16,24,28,30], which include overstrain of the cardiorespiratory system by sympathetic and parasympathetic types and overtraining, but also allow to organize appropriate corrective measures taking into account the most intense systems [31,32]. 
One of the informative methods of express assessments of the functional state of various parts of autonomic regulation and the body as a whole is the method of spectral analysis of variability of the cardiorespiratory system. There are a huge number of publications on the practical application of the method of heart rate variability (HRV), which is widely used in the "field conditions", in various fields of medicine, physiology and sports [1,2,4,5,13,14,18,22,23,25-29,33-38]. In recent years, there have been publications on the practical application in clinical practice, preventive, space and sports medicine of the method of blood pressure variability at each heart contraction [39-44]. We have proposed and implemented in the practice of medical research and medical control of athletes the study of spontaneous respiration variability (RV) for short intervals [45-49].

It should be noted that the search for modern literature sources determining the variability of spontaneous respiration ended in vain. This may be due to the large individual and situational variability of the respiratory system functioning [50-53]. In many studies, the authors research the processes of variability of the cardiovascular system with regard to controlled respiration $[54,55,56,57,58]$, thus focusing on the mechanisms of influence of different frequency respiration. Tests are being developed to investigate the reactivity of the cardiovascular system in response to controlled respiration in various diseases [55,58-60] and conditions of the body [61-64], etc. HRV parameters that do not depend on respiratory rate (RR) are highlighted. In one of the previous studies it was shown that even in spontaneous (uncontrolled) respiration, the parameters of variability of the cardiovascular system significantly depend on RR and tidal volume $\left(\mathrm{V}_{\mathrm{T}}\right)$ [65]. There is a search for criteria for synchronization of the activity of the respiratory and cardiovascular systems $[54,64,66]$.

Given the primacy of the respiratory circuit regulation of HRV [20,50,52,67-69], we proposed to study the variability of spontaneous respiration, because it is an integral indicator that takes into account both the frequency and volume variability of the respiratory process. This indicator can be compared with the respiratory minute volume parameter $\left(V_{E}, l\right)$, which is one of the main indicators of respiratory power, both at rest and at different loads [67]. However, it does not make it possible to distinguish different frequency characteristics of respiration, operating only on generalized values. On the other hand, indicators of respiratory variability, which are calculated using spectral analysis, allow to distinguish different frequency effects, which can significantly supplement the information on regulatory effects on the respiratory system $[20,50]$.

The relevance of this study is due to the feasibility of finding rhythmic criteria for the regulation of respiration in athletes with different types of cardiac rhythm regulation.

The purpose of this work is to determine features of the respiration pattern and its variability in highly qualified athletes with different types of cardiac rhythm regulation.

\section{Materials and Methods}

Our attention was drawn to the integrated method of studying the cardiorespiratory system spiroarteriocardiorhythmography (SACR), which simultaneously records the heart rate, rhythms of systolic and diastolic pressure at each heartbeat and respiratory rhythms [70], which allows significant time savings to determine the functional state of the heart, vessels and respiration, as well as to identify the important parameters of their interaction. SACR is an instrument complex, recommended by Ministry of Health Care and Social Development of the Russian Federation for clinical use; registration certificate \#29/03020703/5869-04, INTOKS, St. Petersburg. Using SACR, 202 highly qualified male athletes aged $22.6 \pm 2.8$ years, who are representatives of acyclic sports, namely various martial arts (karate, taekwondo, kickboxing, boxing, judo, wrestling, sambo) and games (water polo, football) were examined. All studies were conducted in the pre-competition period. The experience of sports was $10.3 \pm 3.1$ years. The study of SACR was performed in the morning, on an empty stomach, in a sitting position. Registration lasted for 2 minutes.

A sample of the registration of the parameters of the cardiorespiratory system of the athlete N. using the device SACR and the results of software analysis of the obtained data is presented in Fig. 1-3. 


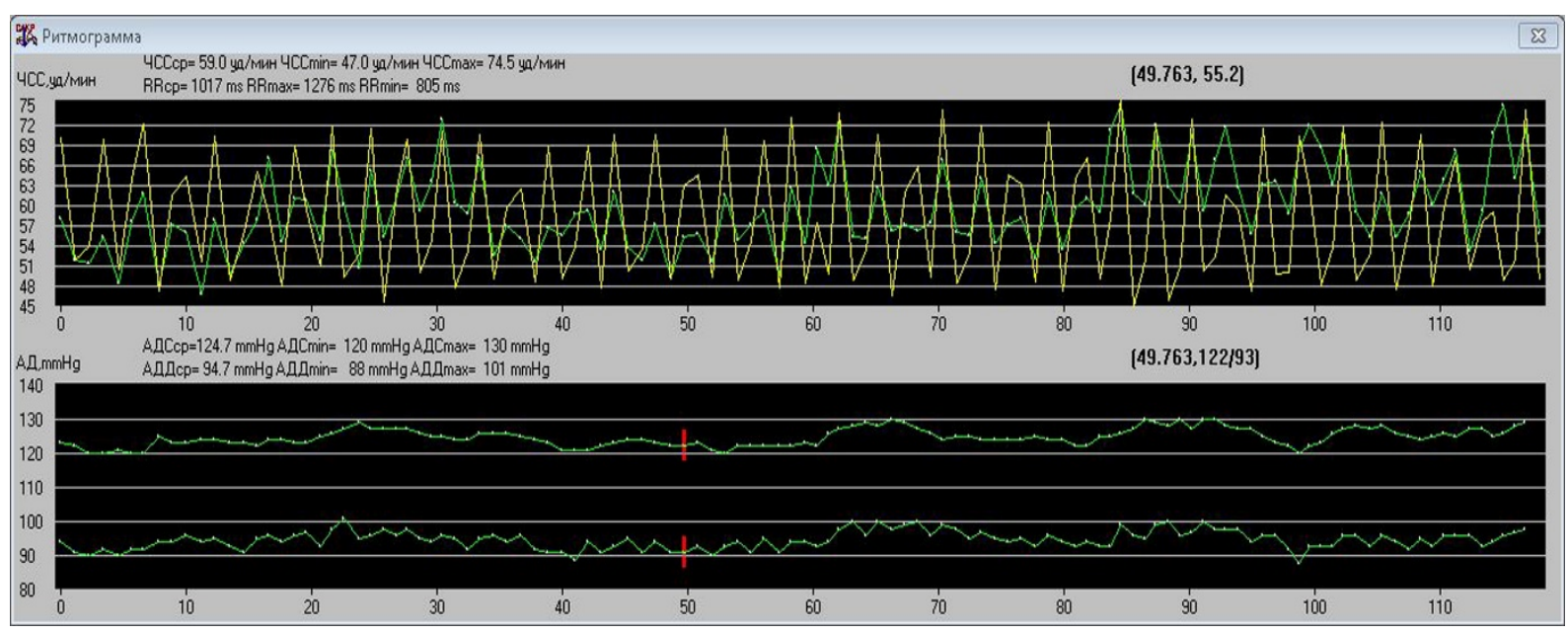

Figure 1. The program window that shows the rhythmograms of heart rate, respiration (in top), systolic and diastolic blood pressure (in bottom)

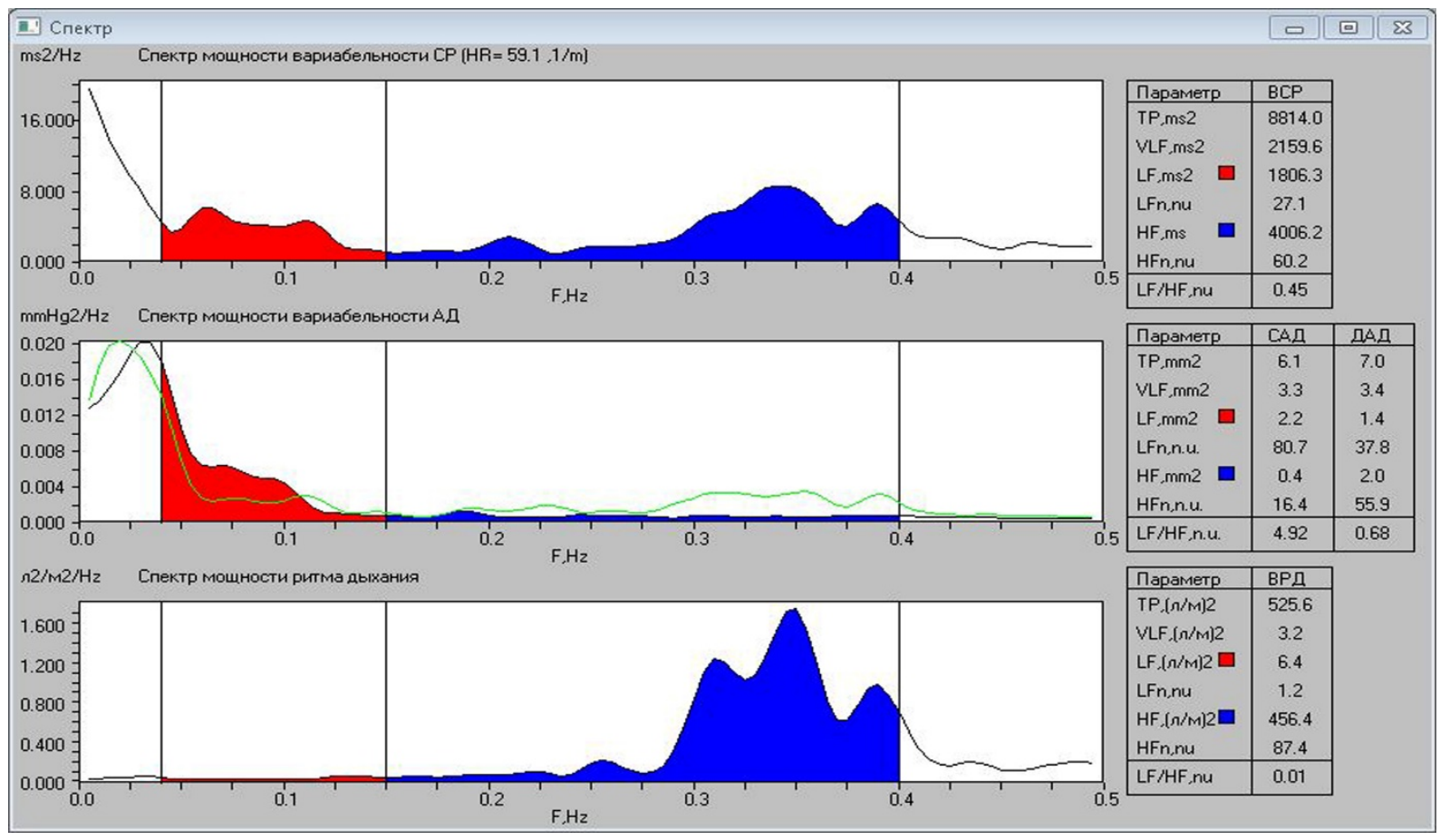

Figure 2. The program window, which shows spectral analysis parameters of heart rate (in top), systolic and diastolic blood pressure (in middle), and respiration (in bottom) 


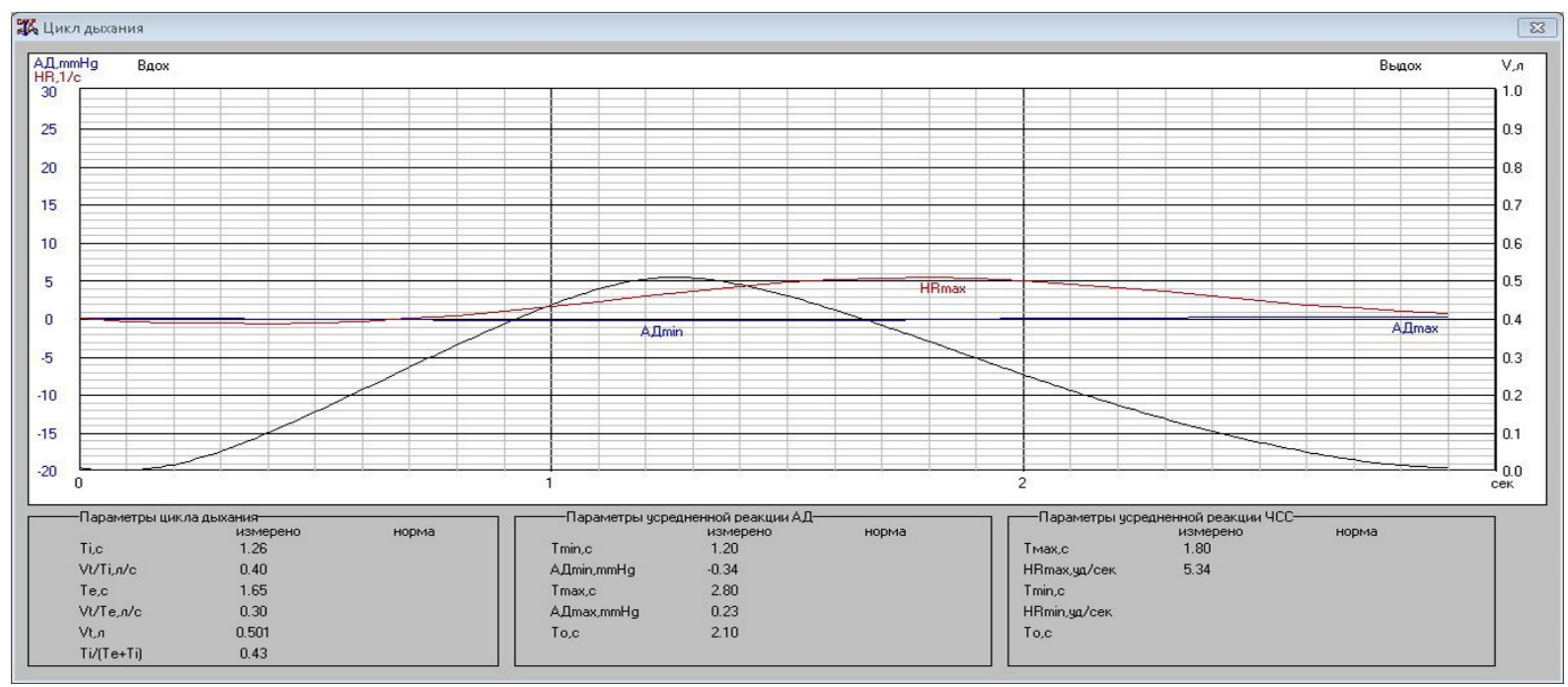

Figure 3. The program window, which shows the analysis of the average parameters of the respiration pattern (black line)

Before the SACR study, morphometric examination and routine methods of measuring arterial systolic pressure (SBP), diastolic pressure (DBP) were performed. HRV indicators were determined: TP (total power of HRV, $\mathrm{ms}^{2}$ ), VLF (power in the very low-frequency range, $\mathrm{ms}^{2}$ ), SI (stress index, conventional units). The ultrasonic sensor of the SACR device allows to measure streams of air on inspiration and expiration and to define average parameters of a pattern of respiration (PR): duration of inspiratory (Tin, s), duration of expiratory (Tex, s), tidal volume $\left(\mathrm{V}_{\mathrm{T}}, \mathrm{l}\right)$, volumetric inspiratory speed (Vin, $\left.\mathrm{l} / \mathrm{s}\right)$, volumetric expiratory speed (Vex, l/s), the ratio of inspiratory duration to expiratory duration (c.u.), as well as the volume of minute respiration $\left(\mathrm{V}_{\mathrm{E}}\right)$; and calculate the parameters of respiration variability (RV): total power of respiration $\left(\mathrm{TP}_{\mathrm{R}},(\mathrm{l} / \mathrm{min})^{2}\right)$, respiration power in the very low-frequency range $\left(\operatorname{VLF}_{\mathrm{R}}(\mathrm{l} / \mathrm{min})^{2}\right)$, respiration power in the low-frequency range $\left(\operatorname{LF}_{\mathrm{R}}(\mathrm{l} / \mathrm{min})^{2}\right)$ and respiration power in the high frequency range $\left(\mathrm{HF}_{\mathrm{R}}(\mathrm{l} / \mathrm{min})^{2}\right)$ and their derivatives $-\mathrm{LF}_{\mathrm{R}} \mathrm{n}$ (a part of low-frequency rhythms in the $\mathrm{RV}$ spectrum, n.u.), $\mathrm{HF}_{\mathrm{R}} \mathrm{n}$ (a part of high-frequency rhythms in the RV spectrum, n.u.), $L F / H F_{R}$ (ratio of $L_{R}$ and $\mathrm{HF}_{\mathrm{R}}$, c.u.).

Shlyk proposed an approach [37], which involves the classification of HRV data to determine the type of the cardiac rhythm autonomic regulation taking into account the indicators of TP $\left(\mathrm{ms}^{2}\right)$, SI (c.u.) and VLF $\left(\mathrm{ms}^{2}\right)$. There are 4 types of autonomic cardiac rhythm regulation: Type I - shows moderate stress, Type II - shows a decrease in the functional state of regulatory systems, the development of fatigue, Type III - shows the optimal state of regulation, Type IV - shows overstrain of autonomic regulation or high fitness.
The principles of classification of types taking into account the above criteria are presented in Table 1.

Statistical analysis was performed using the Statistica 10.0 software to determine the differences between groups using the Mann-Whitney criteria.

Table 1. Criteria for determining the types of cardiac rhythm regulation by N. Shlyk

\begin{tabular}{|c|c|c|c|}
\hline \multirow{2}{*}{ Type of regulation } & \multirow{2}{*}{ Group } & \multicolumn{2}{|c|}{ Criteria } \\
\cline { 2 - 4 } & SI (c.u.) & VLF $\left(\mathrm{ms}^{2}\right)$ \\
\hline $\begin{array}{c}\text { The central regulation } \\
\text { predominance }\end{array}$ & I & $>100$ & $>240$ \\
\cline { 2 - 4 } & II & $>100$ & $<240$ \\
\hline $\begin{array}{c}\text { The autonomous } \\
\text { regulation predominance }\end{array}$ & III & $25-100$ & $>240$ \\
\cline { 2 - 4 } & IV & $<25$ & $\begin{array}{c}\text { VLF }>500, \\
\text { TP }>8000-10000\end{array}$ \\
\hline
\end{tabular}

\section{Results}

According to HRV, the types of cardiac rhythm regulation of athletes were determined. Their distributions with a demonstration of the average values of the main criteria are presented in Table 2.

Characterizing athletes with different types of regulation, attention should be paid to morphometric and routine indicators (Table 3), which differ significantly from all in type IV. They show significantly lower body mass index (BMI, $\mathrm{kg} / \mathrm{m}^{2}$ ), chest circumference $(\mathrm{cm})$ and higher vital index (VI, $\mathrm{kg} / \mathrm{ml}$ ), compared with other athletes $(\mathrm{p}<0.05)$. The parameters of systolic pressure (SBP), diastolic pressure (DBP) and pulse pressure (PBP) are also smaller $(\mathrm{p}<0.05)$. However, DBP does not differ in athletes belonging to type III. Athletes of types I, II and III do not differ significantly from each other. 
Table 2. Average values of HRV indicators, which were the basis for the differentiation of athletes by types of cardiac rhythm regulation, M (Q1;Q3)

\begin{tabular}{|c|c|c|c|c|}
\hline Type of regulation & $\mathrm{n}$ & $\mathrm{TP}, \mathrm{ms}^{2}$ & VLF, $\mathrm{ms}^{2}$ & SI, c.u. \\
\hline Type I & 42 & $2490(1632 ; 3844)$ & $\underline{\mathbf{6 1 0}(\mathbf{3 3 1} ; \mathbf{1 4 0 6})}$ & $\underline{\mathbf{1 4 3 . 4}(\mathbf{1 2 2 . 9} ; \mathbf{2 1 4 . 5})}$ \\
\hline Type II & 28 & $1475(1163 ; 2314)$ & $\underline{\mathbf{1 6 1}(\mathbf{1 4 4} ; \mathbf{1 8 8})}$ & $222.1(150.8 ; 282.8)$ \\
\hline Type III & 88 & $5686(4186 ; 12679)$ & $770(471 ; 1600)$ & $\underline{\mathbf{5 7 . 7}(\mathbf{3 8 . 5} ; \mathbf{7 0 . 3})}$ \\
\hline Type IV & 44 & $\underline{\mathbf{1 8 5 4 0}(\mathbf{1 2 6 4 5} ; \mathbf{2 6 3 9 2})}$ & $\underline{\mathbf{1 4 9 0}(\mathbf{9 9 2} ; \mathbf{2 0 6 1})}$ & $\underline{\mathbf{1 7 . 4}(\mathbf{1 3 . 3} ; \mathbf{1 9 . 9})}$ \\
\hline
\end{tabular}

Table 3. Comparative characteristics of morphometric and routine parameters of athletes with different types of cardiac rhythm regulation, with significant differences, M (Q1;Q3)

\begin{tabular}{|c|c|c|c|c|}
\hline Indicators & Type I & Type II & Type III & Type IV \\
\hline Body mass, kg & $75.0(62.0 ; 84.0)$ & $75.0(70.0 ; 87.0)$ & $73.0(64.0 ; 79.5)$ & $70.7(58.5 ; 82.5)^{@}$ \\
\hline BMI, $\mathrm{kg} / \mathrm{m}^{2}$ & $23.1(21.1 ; 25.2)$ & $22.2(21.4 ; 26.7)$ & $22.5(20.9 ; 24.7)$ & $20.9(20.0 ; 26.2)^{* @ \#}$ \\
\hline Percentage of fat, \% & $11.8(9.8 ; 18.2)$ & $16.8(10.5 ; 18.1)$ & $11.8(8.7 ; 17.0)$ & $10.2(7.3 ; 14.1)^{@}$ \\
\hline Chest circumference (rest), cm & $97.0(88.0 ; 101.0)$ & $97.0(91.5 ; 101.5)$ & $96.0(91.0 ; 100.0)$ & $91.0(87.5 ; 97.0)^{* @ \#}$ \\
\hline Excursion chest, $\mathrm{cm}$ & $7.0(5.0 ; 9.0)$ & $7.0(5.0 ; 8.5)$ & $7.0(6.0 ; 8.0)$ & $8.0(6.0 ; 9.0)^{\#}$ \\
\hline Abdominal circumference, cm & $78.0(73.0 ; 87.0)$ & $78.5(73.5 ; 88.5)$ & $78.0(75.0 ; 84.0)$ & $75.0(73.0 ; 87.0)^{\#}$ \\
\hline VVL, ml & $5000(4100 ; 6000)$ & $4800(4500 ; 5800)$ & $4800(4500 ; 5300)$ & $4650(4200 ; 5600)$ \\
\hline $\mathrm{VI}, \mathrm{ml} / \mathrm{kg}$ & $67.3(62.9 ; 73.7)$ & $64.3(58.8 ; 72.5)$ & $68.2(63.8 ; 72.2)$ & $70.0(66.7 ; 74.7)^{@}$ \\
\hline SBP, mmHg & $120(110 ; 130)$ & $120(116 ; 130)$ & $120(110 ; 130)$ & $110(106 ; 120)^{* @ \#}$ \\
\hline DBP, mmHg & $76(70 ; 80)$ & $76(70 ; 80)$ & $72(64 ; 80)$ & $70(68 ; 80)^{*}$ \\
\hline PBP, mmHg & $50(40 ; 54)$ & $54(40 ; 60)$ & $42(40 ; 50)$ & $40(35 ; 47)^{* @ \#}$ \\
\hline
\end{tabular}

${ }^{*}-\mathrm{p}<0,05$ - between types IV and I; ${ }^{\circledR}-\mathrm{p}<0,05$ - between types IV and II; ${ }^{*}-\mathrm{p}<0,05$ - between types IV and III.

Table 4. Comparative characteristics of respiratory variability parameters in athletes with different types of cardiac rhythm regulation, M (Q1;Q3)

\begin{tabular}{|c|c|c|c|c|}
\hline Indicators & Type I & Type II & Type III & Type IV \\
\hline $\mathrm{TP}_{\mathrm{R}},(\mathrm{l} / \mathrm{min})^{2}$ & $357(286 ; 515)$ & $416(331 ; 888)^{\&}$ & $276(142 ; 538)^{\text {No\$ }}$ & $277(213 ; 339)^{*} @$ \\
\hline $\mathrm{VLF}_{\mathrm{R}},(\mathrm{l} / \mathrm{min})^{2}$ & $1,7(1,0 ; 3,2)$ & $1,7(1,4 ; 2,3)$ & $2,0(0,8 ; 3,6)$ & $2,0(0,9 ; 4,4)$ \\
\hline $\mathrm{LF}_{\mathrm{R}},(\mathrm{l} / \mathrm{min})^{2}$ & $10,2(7,8 ; 25,0)$ & $18,5(6,8 ; 25,0)$ & $15,2(5,3 ; 72,3)$ & $16,0(8,1 ; 66,5)$ \\
\hline $\mathrm{LF}_{\mathrm{R}}$ n, n.u. & $2,7(2,1 ; 8,0)$ & $2,5(1,5 ; 5,7)$ & $4,0(2,1 ; 23,6)$ & $5,9(2,8 ; 36,7)^{* @ @}$ \\
\hline $\mathrm{HF}_{\mathrm{R}},(\mathrm{l} / \mathrm{min})^{2}$ & $276(219 ; 441)$ & $357(286 ; 807)^{8 \&}$ & $205(121 ; 458)^{\text {Nos\$ }}$ & $180(107 ; 260)^{* @ @ ~}$ \\
\hline $\mathrm{HF}_{\mathrm{R}}$ n, n.u. & $83,0(65,8 ; 89,8)$ & $89,4(85,6 ; 91,6)^{\&}$ & $84,1(71,2 ; 91,8)$ & $71,7(51,8 ; 89,8)^{@ \# \#}$ \\
\hline $\mathrm{LFHF}_{\mathrm{R}},(\mathrm{l} / \mathrm{min})^{2} /(\mathrm{l} / \mathrm{min})^{2}$ & $0,03(0,02 ; 0,10)$ & $0,03(0,02 ; 0,06)$ & $0,04(0,02 ; 0,33)$ & $0,09(0,03 ; 0,72)^{* * @ @}$ \\
\hline
\end{tabular}

${ }^{*}-\mathrm{p}<0,05,{ }^{* *}-\mathrm{p}<0,01$ - between types IV and I; ${ }^{@}-\mathrm{p}<0,05,{ }^{@} @-\mathrm{p}<0,01-$ between types IV and II;

${ }^{\#}-\mathrm{p}<0,05$ - between types IV and III; ${ }^{№}-\mathrm{p}<0,05$ - between types III and I; ${ }^{\$}-\mathrm{p}<0,05,{ }^{\$ \$}-\mathrm{p}<0,01$ - between types III and II; ${ }^{\text {\& }}-\mathrm{p}<0,05,{ }^{\text {\&\& }}-\mathrm{p}<$ 0,01 - between types II and I.

The RV parameters turned out to be informative (Table 4). Among all groups, the results of the study of athletes with type IV, which are significantly differentiated from types I and II $(\mathrm{p}<0.01)$ by lower absolute values of the total spectrum of variability $\left(\mathrm{TP}_{\mathrm{R}}\right)$ and high-frequency effects on respiration $\left(\mathrm{HF}_{\mathrm{R}}\right)$. Relatively large in type IV ( $\mathrm{p}$ $<0.05$ ) were also relative indicators of low-frequency effects $\left(\mathrm{LF}_{\mathrm{R}} \mathrm{n}\right)$ and their ratio to high-frequency $\left(\mathrm{LFHF}_{\mathrm{R}}\right)$. The optimal (III) type of cardiac rhythm regulation is differentiated from I and II types $(\mathrm{p}<0.05)$ only by high-frequency effects on respiration $\left(\mathrm{HF}_{\mathrm{R}}\right)$, although the latter is also reflected in the $\operatorname{TP}_{\mathrm{R}}(\mathrm{p}<0.05)$. In this case, types I and II in terms of RV also differ in high-frequency effects on respiration $\left(\mathrm{HF}_{\mathrm{R}}\right)$, which in type II are the largest.

In general, it should be noted that the types of regulation with a predominance of autonomic effects on cardiac rhythm (III and IV) differ from the types of regulation with a predominance of central effects on cardiac rhythm significantly less activity of high-frequency $\left(\mathrm{HF}_{\mathrm{R}},(\mathrm{l} / \mathrm{min})^{2}\right)$ effects on spontaneous respiration, which is displayed on the total power of $\mathrm{RV}$ $\left(\mathrm{TP}_{\mathrm{R}},(\mathrm{l} / \mathrm{min})^{2}\right)$. It is $\mathrm{HF}_{\mathrm{R}}(\mathrm{l} / \mathrm{min})^{2}$ that also differentiates between types I and II, which suggests a significant increase in the reduced functional capacity of the body and the development of fatigue associated with a pronounced predominance of central influences on cardiac rhythm. 
Table 5. Comparative characteristics of respiratory pattern parameters in athletes with different types of cardiac rhythm regulation

\begin{tabular}{|c|c|c|c|c|}
\hline Indicators & Type I & Type II & Type III & Type IV \\
\hline Tin, s & $1.5(1.3 ; 1.8)$ & $1.6(1.4 ; 1.8)$ & $1.6(1.4 ; 2.3)^{\text {No }}$ & $1.7(1.5 ; 2.3)^{* *}$ \\
\hline Tex, s & $2.4(1.8 ; 2.8)$ & $2.1(1.7 ; 2.2)^{\&}$ & $2.5(2.1 ; 3.2)^{\text {\$\$ }}$ & $2.5(2.2 ; 3.8)^{* @ @ ~}$ \\
\hline $\mathrm{V}_{\mathrm{T}}, \mathrm{l}$ & $0.550(0.400 ; 0.770)$ & $0.690(0.460 ; 0.770)$ & $0.530(0.380 ; 0.760)$ & $0.525(0.425 ; 0.745)$ \\
\hline $\mathrm{Vin}, \mathrm{l} / \mathrm{s}$ & $0.32(0.26 ; 0.42)$ & $0.37(0.29 ; 0.44)^{\&}$ & $0.27(0.20 ; 0.36)^{\text {NoS\$ }}$ & $0.28(0.22 ; 0.32)^{* *} @$ \\
\hline $\mathrm{Vex}, \mathrm{l} / \mathrm{s}$ & $0.26(0.22 ; 0.32)$ & $0.28(0.22 ; 0.38)$ & $0.20(0.16 ; 0.31)^{\text {Nos }}$ & $0.23(0.16 ; 0.30)^{* @}$ \\
\hline $\mathrm{Tin} / \mathrm{Tex}$ & $0.70(0.60 ; 0.76)$ & $0.77(0.63 ; 0.82)^{\&}$ & $0.71(0.63 ; 0.80)$ & $0.67(0.59 ; 0.81)^{@}$ \\
\hline $\mathrm{RR}, \min ^{-1}$ & $15.2(13.3 ; 18.5)$ & $16.2(10.9 ; 19.3)$ & $14.8(11.1 ; 16.9)^{\$}$ & $13.5(9.1 ; 15.8)^{* @ @}$ \\
\hline $\mathrm{V}_{\mathrm{E}}, \mathrm{l}$ & $8.4(7.3 ; 10.0)$ & $8.0(7.4 ; 11.0)$ & $6.6(4.8 ; 10.1)^{\text {NoS\$ }}$ & $7.4(5.1 ; 9.4)^{* @ @}$ \\
\hline
\end{tabular}

$*-\mathrm{p}<0,05, * *-\mathrm{p}<0,01-$ between types IV and I; ${ }^{@}-\mathrm{p}<0,05,{ }^{@} @-\mathrm{p}<0,01-$ between types IV and II;

№ $-\mathrm{p}<0,05$ - between types III and I; ${ }^{\$}-\mathrm{p}<0,05,{ }^{\$ \$}-\mathrm{p}<0,01$ - between types III and II; ${ }^{*}-\mathrm{p}<0,05-$ between types II and I.

Analyzing the differences in respiratory pattern (PR) of athletes with different types of cardiac rhythm regulation, first of all (Table 5), it is necessary to pay attention to persons with type IV, who have a significantly lower RR - $13.5(9.1 ; 15.8)$ than athletes with type I and type II 15.2 (13.3; 18.5), $\mathrm{p}<0.05$, and 16.2 (10.9; 19.3), $\mathrm{p}<0.01$. This is due to a significant increase in both inspiration time and expiration time in type IV, which is associated with lower volumetric inspiratory and expiratory speeds compared to types I and II. In this case, the ratio of the phases of respiration does not differ significantly. Almost similar, but less significant, are the differences in PR of athletes with type III regulation. No differences were registered between their $\mathrm{PR}$ and $\mathrm{PR}$ of athletes from type IV. Athletes belonging to types I and II of regulation are differentiated in some way according to PR. First of all, this applies to a significant reduction in expiratory duration in type II regulation ( $p<0.05)$, which is accompanied only by a tendency to increase the volumetric expiratory speed compared to type I. This PR is evidenced by an increase in the ratio of the phases of inspiration and expiration, which in athletes from type II is significantly higher than in athletes from type I - 0.77 (0.63; 0.82$)$ against $0.70(0.60 ; 0.76), \mathrm{p}<0.05$. The latter may indicate a certain inferiority of the expiratory phase in type II.

That is, the types of regulation that are associated with the predominance of autonomic effects on cardiac rhythm (III and IV) have significant differences in PR. They characterize more economical spontaneous respiration, which against the background of similar values of $\mathrm{V}_{\mathrm{T}}(\mathrm{l})$, which is a criterion of oxygen supply to the body, are determined by the prolongation of inspiration (s) and expiration (s), decrease in volumetric inspiratory and expiratory speed (l/s) and a corresponding reduction in RR $\left(\mathrm{min}^{-1}\right)$ and $\mathrm{V}_{\mathrm{E}}$ (l). Noteworthy are the differences between types II and I, which reflect the level of centralization of effects on cardiac rhythm. Indicative, in this comparison, is a certain dissociation of the differences between the indicators of the duration of inspiration (s) and expiration (s) with the indicators of the volumetric speed of inspiration and expiration (l/s).

A significant decrease in expiration in type II is accompanied by similar to type I values of expiration. And similar values of inspiration at the II type are followed by essential increase in inspiration. This can be explained by the inefficiency of expiration in type II, when the increase in hypercapnia, which is characteristic of a decrease in the reserve capacity of the cardiovascular system, leads to premature overstimulation of the respiratory center and activating effects on the inspiratory muscles [9].

Among all indicators of $\mathrm{RV}$ the indicator of $\mathrm{HF}_{\mathrm{R}}$, $(\mathrm{l} / \mathrm{min})^{2}$ deserves the greatest attention. Therefore, it was important to trace its connections in different types of cardiac rhythm regulation with other studied parameters. First of all, it was shown (Table 6) that among the indicators that determine the type of cardiac rhythm regulation, significant negative correlations were observed with the parameters of total power HRV $\left(\mathrm{ms}^{2}\right)$ with excessive centralization (type II) and excessive autonomy (type IV) regulation. This suggests that HF-effects on spontaneous respiration in some way compensate for the pronounced regulatory effects on cardiac rhythm increasing $\left(\mathrm{HF}_{\mathrm{R}},(\mathrm{l} / \mathrm{min})^{2}\right)$ with decreasing $\left(\mathrm{HF}, \mathrm{ms}^{2}\right)$ - type $\mathrm{II}$, and decreasing $\left(\mathrm{HF}_{\mathrm{R}},(\mathrm{l} / \mathrm{min})^{2}\right)$ with increasing $\left(\mathrm{HF}, \mathrm{ms}^{2}\right)$ - type IV. The latter was also shown by us in the analysis of RV parameters of athletes with different levels of somatic health, which is based on the level of maximal oxygen consumption $\left(\mathrm{VO}_{2} \max \right)$ [62], changes in the regulation of the cardiorespiratory system in the dynamics of the annual training cycle [15], as well as in determining RV changes in competitive [46] and training load [47,48]. No such association has been established with other components of HRV that determine the type of cardiac rhythm regulation.

Given the relationship of $\mathrm{HF}_{\mathrm{R}}$ with $\mathrm{PR}$ parameters (Table 7), it should be noted that significant there are relationships with volumetric speeds of inspiration (Vin, l/s) and expiration (Vex, l/s), due to the peculiarities calculation of RV power indicators, including in the $\mathrm{HF}$ range. At the same time, the least significant are the 
connections of athletes with types II and IV of cardiac rhythm regulation, in which Vin and Vex are well differentiated. It is noteworthy that most of the connections (moreover, similar in strength) in this indicator RV with PR indicators are observed in types II and III, which suggests a significant role of rhythmic components of spontaneous respiration associated with central control mechanisms, in ensuring optimal (type III) regulation of cardiac rhythm and its greatest intensity (type II), when chemoreceptors are activating. On the other hand, a lot number of factors that may affect the mechanisms of spontaneous respiration regulation, in this case, limited the possibilities of more meticulous analysis.

Such factors include morphometric characteristics of body structure, which determine its constitutional features. As shown by the analysis of the relationship of $\mathrm{HF}_{\mathrm{R}}$ with the parameters of morphometry of athletes (Table 8), they differ significantly in athletes with centralization (types I and II) and autonomy (types III and IV) of cardiac rhythm regulation. In type III (optimal) regulation, lower values of $\mathrm{HF}_{\mathrm{R}}$ (Table 4) are associated with chest circumference at rest $(\mathrm{cm})$, the circumference of the abdomen $(\mathrm{cm})$ and significantly higher values of $\mathrm{VI}(\mathrm{ml} / \mathrm{kg})$.

In type IV regulation, they are associated with body mass index $(\mathrm{cm})$, chest girth at rest $(\mathrm{cm})$ and abdominal circumference $(\mathrm{cm})$. The parameters of lung capacity in type IV are not significant. They are also not significant in types I and II of heart rate regulation. However, with a marked decrease in functional reserves (type II) the leading link is related to a chest excursion, which indicates an increase in $\mathrm{HF}_{\mathrm{R}}$ with increasing excursion. The latter suggests that an additional source of HF-effects on spontaneous respiration with reduced functional status may be excessive irritation of mechanoreceptors of the chest, which may also contribute to the inferiority of the expiratory phase, which we suggested above.

Table 6. Correlation matrix of $\mathrm{HF}_{\mathrm{R}},(\mathrm{l} / \mathrm{min})^{2}$ with $\mathrm{HRV}$ parameters, which determine the type of cardiac rhythm regulation

\begin{tabular}{|c|c|c|c|c|}
\hline Indicator & Type & TP, $\mathrm{ms}^{2}$ & VLF, $\mathrm{ms}^{2}$ & SI, c.u. \\
\hline \multirow{3}{*}{$\mathrm{HF}_{\mathrm{R}},(\mathrm{l} / \mathrm{min})^{2}$} & Type I & 0.290 & 0.273 & -0.106 \\
\cline { 2 - 5 } & Type II & $\mathbf{- 0 . 6 2 7}^{*}$ & 0.186 & 0.022 \\
\cline { 2 - 5 } & Type III & -0.216 & -0.073 & 0.287 \\
\cline { 2 - 5 } & Type IV & $\mathbf{- 0 . 4 4 4 ^ { * }}$ & -0.083 & 0.299 \\
\hline
\end{tabular}

$*-\mathrm{p}<0,05$

Table 7. Correlation matrix of $\mathrm{HF}_{\mathrm{R}},(\mathrm{l} / \mathrm{min})^{2}$ with $\mathrm{PR}$ parameters at sportsmen with different types of cardiac rhythm regulation

\begin{tabular}{|c|c|c|c|c|c|c|c|}
\hline Indicator & Type & Tin, $\mathrm{s}$ & Tex, s & $\mathrm{V}_{\mathrm{T}}, \mathrm{l}$ & Vin, l/s & Vex, l/s & $\mathrm{RR}, \min ^{-1}$ \\
\hline \multirow{4}{*}{$\mathrm{HF}_{\mathrm{R}},(\mathrm{l} / \mathrm{min})^{2}$} & Type I & 0.107 & -0.058 & $0.709^{* *}$ & $0.789^{* * *}$ & $0.776^{* * *}$ & 0.010 \\
\hline & Type II & $-0.320^{*}$ & $-0.497^{*}$ & $0.468^{*}$ & $0.769^{* *}$ & $0.961^{* * *}$ & $0.328^{*}$ \\
\hline & Type III & $-0.317^{*}$ & $-0.437^{* *}$ & $0.327^{*}$ & $0.752^{* * *}$ & $0.876^{* * *}$ & $0.477^{* *}$ \\
\hline & Type IV & $-0.436^{*}$ & -0.296 & 0.067 & $0.518^{*}$ & $0.725^{* * *}$ & $0.356^{*}$ \\
\hline
\end{tabular}

$*-\mathrm{p}<0,05, * *-\mathrm{p}<0,01, * * *-\mathrm{p}<0,001$

Table 8. Correlation matrix of $\mathrm{HF}_{\mathrm{R}},(\mathrm{l} / \mathrm{min})^{2}$ with morphometric indicators at sportsmen with different types of cardiac rhythm regulation

\begin{tabular}{|c|c|c|c|c|c|c|c|}
\hline \multirow{2}{*}{ Indicator } & Type & BMI, $\mathrm{kg} / \mathrm{m}^{2}$ & $\begin{array}{c}\text { Chest } \\
\text { circumference } \\
\text { (rest), cm }\end{array}$ & $\begin{array}{c}\text { Excursion chest, } \\
\mathrm{cm}\end{array}$ & $\begin{array}{c}\text { Abdominal } \\
\text { circumference } \\
\text { (rest), cm }\end{array}$ & VVL, ml & VI, ml/kg \\
\hline \multirow{3}{*}{$\mathrm{HF}_{\mathrm{R}},(\mathrm{I} / \mathrm{min})^{2}$} & Type I & 0.156 & 0.193 & -0.190 & 0.134 & 0.134 & -0.154 \\
\cline { 2 - 9 } & Type II & -0.086 & 0.032 & $\mathbf{0 . 5 1 9}^{*}$ & -0.152 & 0.151 & 0.203 \\
\cline { 2 - 9 } & Type III & 0.280 & $\mathbf{0 . 3 5 8}^{*}$ & 0.106 & $\mathbf{0 . 3 2 1}^{*}$ & 0.072 & $\mathbf{- 0 . 6 1 3}^{* * *}$ \\
\cline { 2 - 8 } & Type IV & $\mathbf{0 . 5 2 0}$ & $\mathbf{0 . 5 1 2}^{*}$ & -0.167 & $\mathbf{0 . 4 6 6}^{*}$ & 0.302 & -0.221 \\
\hline
\end{tabular}

$*-\mathrm{p}<0,05, * *-\mathrm{p}<0,01, * * *-\mathrm{p}<0,001$ 


\section{Discussion}

Our results indicate that athletes with the different types of cardiac rhythm regulation at rest are differentiated by $\mathrm{PR}$ and RV. The most significant among the indicators of $\mathrm{RV}$ were absolute indicators $-\mathrm{TP}_{\mathrm{R}}$, $(\mathrm{l} / \mathrm{min})^{2}$ and $\mathrm{HF}_{\mathrm{R}}$, $(\mathrm{l} / \mathrm{min})^{2}$. However, their low values are associated not only with the optimal and high level of cardiac rhythm regulation, but also indicate a significant economization of the respiratory system. This assumption is confirmed by the data obtained by us earlier in the survey of highly qualified athletes in the competitive period, when the results of the study of $\mathrm{RV}$ the next morning after intense competitive exercise indicated the differentiation of athletes in $\mathrm{TP}_{\mathrm{R}},(\mathrm{l} / \mathrm{min})^{2}$ and $\mathrm{HF}_{\mathrm{R}},(\mathrm{l} / \mathrm{min})^{2}$, and high values of the latter were observed in athletes with signs of under recovery [46].

These indicators had characteristic dynamics under the influence of intense training loads in the pre-competition period, which indicated the possibility of the development of functional overstrain by sympathetic and parasympathetic types $[47,48]$. The data obtained in the study of patients with different courses of bronchial asthma, which indicate a significant (several times) increase in $\mathrm{TP}_{\mathrm{R}},(\mathrm{l} / \mathrm{min})^{2}, \mathrm{LF}_{\mathrm{R}},(\mathrm{l} / \mathrm{min})^{2}$ and $\mathrm{HF}_{\mathrm{R}},(\mathrm{l} / \mathrm{min})^{2}$ were quite informative in comparison with healthy individuals, especially in the intermittent course [35], which is considered as a mechanism for compensating for obstructive disorders. The latter in the examination of athletes may be useful to determine the preconditions for the development of exercise-induced asthma. On the other hand, the authors [49] show that in the persistent course there is a pronounced dependence of RV on body weight, especially excessive one. The study of rhythmic parameters of spontaneous respiration can be informative in the study of synchronization of the cardiorespiratory system, which have now begun to be actively determined by simultaneous registration of parameters of the cardiovascular and respiratory systems [54,59,60].

This approach, in our opinion, will diagnose the subtle mechanisms of intersystem interactions that underlie the pre-pathological changes in the body of athletes.

\section{Conclusions}

A study of the variability and pattern respiration in athletes with different types of cardiac rhythm regulation revealed the following:

1. When at rest, athletes with a predominance of central (types I and II) and autonomous (types III and IV) effects on cardiac rhythm are differentiated by indicators of total respiratory power $\left(\mathrm{TP}_{\mathrm{R}},(\mathrm{l} / \mathrm{min})^{2}\right)$ and power in the high frequency range $\left(\mathrm{HF}_{\mathrm{R}}\right)$, $\left.(1 / \mathrm{min})^{2}\right)$, which with the predominance of autonomous influences are significantly smaller.
2. Athletes with type IV cardiac rhythm regulation have a more significant contribution of the low-frequency component $\left(\mathrm{LF}_{\mathrm{R}} \mathrm{n}\right.$, n.u.) in the regulation of spontaneous respiration than athletes with type I and II cardiac rhythm regulation, which is also reflected in the ratio of low-frequency and high-frequency effects $\left(\mathrm{LFHF}_{\mathrm{R}},(\mathrm{l} / \mathrm{min})^{2} /(\mathrm{l} / \mathrm{min})^{2}\right)$.

3. Athletes with type I and II cardiac rhythm regulation are differentiated by indicators of total respiratory power $\left(\mathrm{TP}_{\mathrm{R}},(\mathrm{l} / \mathrm{min})^{2}\right)$ and power in the high frequency range $\left(\mathrm{HF}_{\mathrm{R}},(\mathrm{l} / \mathrm{min})^{2}\right)$, which in type II are significantly higher.

4. When at rest, athletes with a predominance of central (types I and II) and autonomous (types III and IV) effects on cardiac rhythm are differentiated by the indicators of the respiration pattern - durations of inspiration (s) and expiration (s), which during the predominance of autonomous influences is significantly greater; at that time the volumetric inspiratory speed (l/s), volumetric expiratory speed (l/s) and VE (l) are a significantly lower while the predominance of autonomous influences. In this case, $\mathrm{V}_{\mathrm{T}}$ (l) and the ratio of the phases of inspiration and expiration do not differ significantly.

5. It is shown that in type II regulation of cardiac rhythm there is a significant decrease in expiratory duration (s), which is also manifested by a significant increase in the ratio of inspiratory and expiratory phases, which may characterize expiratory insufficiency in this type.

\section{Ethical Approval}

All the participants in all series of the experiment signed informed consent forms. Compliance with international laws (including the Helsinki Declaration as revised in 2013) and Ukrainian laws, as regards the legal and ethical principles of scientific research with human participation, was confirmed by the decision of the Ethics Committee of the Lviv state university of physical culture n.a. Ivan Boberskiy.

\section{REFERENCES}

[1] Bourdon P., Cardinale M., Murray A., Gastin P., Kellmann M., Varley M., Gabbett T., Coutts A., Burgess D., Gregson W. "Monitoring athlete training loads: consensus statement", Int J Sport Phys Perform, no. 12, pp. S2161-S2170, 2017. doi: 10.1123/IJSPP.2017-0208

[2] Gavrilova E. "Sport, stress, variability", Moscow, Sport, 2015. (in Russ.).

[3] Guzii O. "Changes of types of autonomous regulation of a heart rhythm under the influence of intense physical loads", 
Scientific journal National Pedagogical Dragomanov University, vol. 10, no. 118, pp. 43-49, 2019. (In Ukr.).

[4] Guzii O., Romanchuk A., Maglovanyy A., Trach V. "Polyfunctional express-evaluation criteria of the sportsman organism state”, Journal of Physical Education and Sport, vol. 19, no. 4, pp. 2352-2358, 2019. doi: 10.7752/jpes.2019.04356

[5] Pankova N., Bogdanova E., Karganov M., Eygel M., Kuznetsov P., Simakov O. "After-load Dynamics of Cardiovascular System Parameters in Young Athletes (results obtained by method of Spiroarteriocardiorythmogra phy)”, Valeology, no. 3, pp. 54-60, 2013. (in Russ.).

[6] Romanchuk A., Ovcharek A., Braslavsky I. "Vegetative provision of the cardiorespiratory system of athletes of various specializations", Theory and practice of physical culture, no. 7, pp. 48-50, 2006. (in Russ.)

[7] Romanchuk A., Dolgier Y. "Effects of long-term training experience of aerobic exercises on middle-aged women”, Journal of Physical Education and Sport, vol. 17, no. 2, pp. 680-687, 2017. doi: 10.7752/jpes.2017.02102.

[8] De Haan, D. "A Review of the Appropriateness of Existing Micro- and Meso-level Models of Athlete Development within Equestrian Sport”, International Journal of Human Movement and Sports Sciences, vol. 5, no. 1, pp. 1-8, 2017. doi: 10.13189/saj.2017.050101

[9] Botek M., McKune A., Krejci J., Stejskal P., Gaba, A. "Change in Performance in Response to Training Load Adjustment Based on Autonomic Activity", Int J Sports Med, vol. 35, no. 06, pp. 482-488, 2014. doi: $10.1055 / \mathrm{s}-0033-1354385$

[10] Bosquet L., Merkari S., Arvisais D., Aubert A. "Is heart rate a convenient tool to monitor over-reaching? A systematic review of the literature”, Br J Sports Med, vol. 42, no. 9, pp. 709-14, 2008. doi: 10.1136/bjsm.2007.042200.

[11] Cadegiani F., Claudio E.. "Novel Insights of Overtraining Syndrome Discovered from the EROS Study”, BMJ Open Sport \& Exercise Medicine, vol. 5, no. 1, p. e000542, 2019. doi:10.1136/bmjsem-2019-000542.

[12] Guzii O., Romanchuk A. "Heart rate variability during controlled respiration after endurance training”, Journal of Physical Education and Sport, vol. 17, no. 3, pp. 2024-2029, 2017. doi: 10.7752/jpes.2017.03203.

[13] Guzii O.; Romanchuk A. Differentiation of Hemodynamics of Top Athletes Depending on Heart Rate Variability after Training, J Adv Med Med Res, vol. 22, no. 3, pp. 1-10, 2017. doi: 10.9734/JAMMR/2017/33619.

[14] Nakamura F., Pereira L., Rabelo F., Flatt A., Esco M., Bertollo M., Loturco I. "Monitoring weekly heart rate variability in futsal players during the preseason: the importance of maintaining high vagal activity”, J Sport Sci, no. 34, pp. 2262-2268, 2016. doi: $10.1080 / 02640414.2016 .1186282$

[15] Romanchuk A. "Features of Autonomic Regulation of Cardiorespiration System in Dynamics of Training Cycle of Year”, Theory and practice of physical culture, no. 6, pp. 4245, 2005. (in Russ.).

[16] Taylor K., Chapman D., Cronin J., Newton M., Gill N.
"Fatigue Monitoring in High Performance Sport: A Survey of Current Trends”, J Aust Strength Cond, vol. 20, no. 1, pp. 12-23, 2012.

[17] Agajanyan N., Baevskiy R., Berseneva A. "Adaptation problems and the doctrine of health”. Moscow, Publishing house of RUDN, 2006. (in Russ.).

[18] da Silva V., de Oliveira N., Silveira H., Mello R., Deslandes A. "Heart rate variability indexes as a marker of chronic adaptation in athletes: A systematic review", Ann Noninv Electrocard, no. 20, pp. 108-118, 2015. doi:10.1111/anec.12237

[19] Guziy O., Romanchuk A. "Sensitivity of arterial baroreflex in the terms of body recovery after training load", Zaporozhye Medical Jour, vol. 3, no. 96, pp. 24-30, 2016. doi:10.14739/2310-1210.2016.3.76922 (In Ukr.).

[20] Karemaker J. “An introduction into autonomic nervous function”, Physiol Meas, no. 38, pp. R89-R118, 2017. doi: 10.1088/1361-6579/aa6782

[21] Pankova N. "Mechanisms of short-term and long-term adaptation”, Pathogenesis, vol. 18, no. 3, pp. 77-86, 2020. doi: 10.25557/2310-0435.2020.03.77-86. (in Russ.).

[22] Pankova N., Alchinova I., Cherepov A., Yakovenko E., Karganov M. "Cardiovascular system parameters in participants of arctic expeditions”. International Journal of Occupational Medicine and Environmental Health, vol. 33, no. 6, pp. 1-10, 2020. doi: 10.13075/ijomeh.1896.01628

[23] Ternovoi K., Romanchuk A., Sorokin M., Pankova N. "Characteristics of the Functioning of the Cardio-Respiratory System and Autonomic Regulation in Para-Athletes with Spinal Injury”, Hum Physiol, vol. 38, no. 4, pp. 410-415, 2012. doi: 10.1134/S0362119712040147

[24] Thiene G., Carturan E., Corrado D. "Prevention of sudden cardiac death in the young and in athletes: dream or reality?", Cardiovasc Pathol, no. 6, pp. 15-17, 2010. doi: 10.1016/j.carpath.2009.04.001

[25] Chen Y., Clemente F., Bezerra P., Lu Y. "Ultra-short-term and Short-term Heart Rate Variability Recording during Training Camps and an International Tournament in U-20 National Futsal Players”, Int J Environ Res Public Health, vol. 17, no. 3, pp. 775, 2020. doi: 10.3390/ijerph17030775

[26] Hernando D., Garatachea N., Almeida R., Casajús J., Bailón R. "Validation of Heart Rate Monitor Polar RS800 for Heart Rate Variability Analysis During Exercise”, J Str Cond Res, vol. 32, no. 3, pp. 716-725, 2018. doi: 10.1519/JSC.0000000000001662

[27] Nakamura F., Antunes P., Nunes C., Costa J., Esco M., Travassos B. "Heart Rate Variability Changes From Traditional vs. Ultra-Short-Term Recordings in Relation to Preseason Training Load and Performance in Futsal Players”, The J Str Cond Res, vol. 34, no. 10, pp. 2974-2981, 2020. doi: 10.1519/JSC.0000000000002910

[28] Baumert M., Brechtel L., Lock J., Hermsdorf M., Wolff R., Baier V., Voss A. "Heart rate variability, blood pressure variability, and baroreflex sensitivity in overtrained athletes”, Clin J Sport Med, vol. 16, no. 5, pp. 412-417, 2006. doi: 10.1097/01.jsm.0000244610.34594.07.

[29] Guzii O., Romanchuk A. "Determinants of the functional 
state of sportsmen using heart rate variability measurements in tests with controlled respiration”, Journal of Physical Education and Sport, vol. 18, no. 2, pp. 715-724, 2018. doi: 10.7752/jpes.2018.02105.

[30] Ten Haaf T., van Staveren S., Oudenhoven E., Piacentini M., Meeusen R., Roelands B., Koenderman L., Daanen H, Foster C., de Koning J. "Prediction of functional overreaching from subjective fatigue and readiness to train after only 3 days of cycling”. Int J Sports Physiol Perform, no. 12, Suppl. 2, pp. 287-294, 2017. doi: 10.1123/ijspp.2016-0404

[31] Guzii O., Vovkanych A. "Physical therapy tools in recovery of athletes' body during training process”, Sport science of Ukraine, vol. 6, no. 88, pp. 11-19, 2018. (In Ukr.)

[32] Wiewelhove T., Schneider C., Do“weling A., Hanakam F., Rasche C., Meyer T. "Effects of different recovery strategies following a half-marathon on fatigue markers in recreational runners”, PLoS ONE, vol. 13, no. 11, e0207313, 2018. doi: 10.1371/journal.pone.0207313

[33] Akselrod S., Gordon D., Madwed J., Snidman N., Shannon D., Cohen R. "Hemodynamic regulation: investigation by spectral analysis”, Am J Physiol, no. 249, pp. H867-875, 1985. doi: 10.1152/ajpheart.1985.249.4.H867

[34] Bayevskiy R. "Heart Rate Variability Analysis: History, Philosophy, Theory, and Practice", Klinicheskaya informatika i telemeditsina, vol.1, no.1, pp. 54-65, 2004. (in Russ.).

[35] Romanchuk A., Bazhora Ya. "Regulatory peculiar features of uncontrolled bronchial asthma", Journal of Education, Health and Sport, vol. 8, no. 1, pp. 330-346, 2018. doi: 10.5281/zenodo.1405627

[36] Shlyk N. "Management of athletic training taking into account individual heart rate variability characteristics", Hum Physiol, vol.42, no. 6, pp. 655-664, 2016. doi: $10.1134 /$ S0362119716060189

[37] Shlyk N, Sapozhnikova E, Kirillova T, Semenov V. "Typoloagical characteristics of the functional state of regulatory systems in schoolchildren and young athletes (according to heart rate variability data)", Hum Physiol, vol. 35, no. 6, pp. 730-738, 2009

[38] Shlyk N., Lebedev E., Vershinina O. "Athletic training process quality rating by express tests of heart rate variability in view of individual type of regulation”, Theory and Practice of Physical Culture, no. 2, pp. 18-20, 2019.

[39] Castiglioni P., Parati G., Civijian A., Quintin L., Di Rienzo M. "Local scale exponents of blood pressure and heart rate variability by detrended fluctuation analysis: effects of posture, exercise, and aging”, IEEE Trans Biomed Eng, vol. 56, no. 3, pp. 675-684, 2009. doi: 10.1109/TBME.2008.20 05949.

[40] Cherepov A., Pozdeeva D., Arkhipova E. "The Choice of Informative Parameters of the Cardiovascular System for Assessment of Physiological Effects of Hypogravity”, American Journal of Life Sciences. Special Issue: Space Flight Factors: From Cell to Body, vol. 5, no. 1-2, pp. 48-57, 2014. doi: 10.11648/j.ajls.s.2015030102.18

[41] Parati G., Ongaro G., Bilo G., Glavina F., Castiglioni P., Di Rienzo M., Mancia G. "Non-invasive beat-to-beat blood pressure monitoring: new developments", Blood Press
Monit, vol. 8, no. 1, pp. 31-36, 2003. doi: 10.1097/00126097-200302000-00007

[42] Parati G., Stergiou G., Dolan E., Bilo G. "Blood pressure variability: clinical relevance and application”, Journal of Clinical Hypertension, vol. 20, no. 7, pp. 1133-1137, 2018. doi: $10.1111 /$ jch.13304

[43] Romanchuk A., Guzii O. "Level of Athlete's Health and Blood Pressure Variability”, Biomed J Sci\&Tech Res, vol. 10, no. 3, 2018. doi: 10.26717/ BJSTR.2018.10.001943

[44] Wesseling K. "Finapres, continuous noninvasive finger arterial pressure based on the method of Peñáz". In: Meyer-Sabellek W., Gotzen R., Anlauf M., Steinfeld L. (eds) “Blood Pressure Measurements”. Steinkopff. 1990.

[45] Panenko A, Romanchuk O. "To the question of age-related characteristics of breathability variability", Odeskyi medychnyi zhurnal, no. 5, pp. 63-66, 2004. (Ukr.)

[46] Romanchuk A., Guzii O. "Respiration variability of athletes after competition load”, Rev Bras Med Esporte, vol. 24, no. 5, Suppl.1, p. 78, 2018.

[47] Romanchuk A., Guzii O. "Peculiarities of Changes in Respiratory Variability under the Influence of Training Load in Athletes with Cardiovascular Overstrain by Sympathetic Type", International Journal of Education and Science, vol. 3, no. 2, p. 54, 2020. doi: 10.26697/ijes.2020.2.38

[48] Romanchuk A., Guzii O. "Features of Respiratory System Regulation at Formation of an Overstrain of Cardiovascular System by Parasympathetic Type”, Fìz reabìl rekreac-ozdor tehnol, vol. 3, no. 1, pp. 17-22, 2020. (In Ukr.)

[49] Bazhora Ya., Romanchuk O. "Variability and Respiration Pattern of Patients with Persistent Asthma and Obesity", Ukraïns'kij Žurnal Medicini, Bìologii ta Sportu, vol. 3, no. 7, pp. 74-83, 2018. doi: 10.26693/jmbs03.07.074 (In Ukr.)

[50] Eckberg D. "Physiological basis for human autonomic rhythms”, Ann Med, vol. 32, no. 5, pp. 341-349, 2000. doi: 10.3109/07853890008995937

[51] Saboul D., Pialoux V., Hautier C. "The impact of breathing on HRV measurements: implications for the longitudinal follow-up of athletes”, Eur J Sport Sci, no. 13, pp. 534-542, 2013. doi: 10.1080/17461391.2013.767947

[52] Shik L. "The main features of the control of respiration. Physiology of breathing", SPb., Nauka, 1994. (in Russ.).

[53] van den Aardweg J., Karemaker J. "Respiratory variability and associated cardiovascular changes in adults at rest”, Clin Physiol, vol. 11, no. 2, pp. 95-118, 1991. doi: 10.1111/j.1475-097x.1991.tb00103.x

[54] Noskin L., Rubinskiy A., Romanchuk A., Marchenko V., Pivovarov V., Cherepov A., Zarovkina L. "Study of cardiovascular and respiratory synchronization in different types of breathing”, Pathogenesis, vol. 16, no. 4, pp. 90-96, 2018. doi: 10.25557/2310-0435.2018.04.90-96. (in Russ.).

[55] Romanchuk O., Velychko V., Bazhora Ya. "Reactivity of cardiorespiratory system in bronchial asthma patients according to the tests with respiratory maneuvers performance”, Zaporozhye Medical Jour, vol. 4, no. 115, pp. 449-457, 2019. doi: 10.14739/2310-1210.2019.4.173191 (In Ukr.) 
[56] Shinba T., Inoue T., Matsui T., Kimura K., Itokawa M., Arai M. "Changes in Heart Rate Variability after Yoga are Dependent on Heart Rate Variability at Baseline and during Yoga: A Study Showing Autonomic Normalization Effect in Yoga-Naïve and Experienced Subjects”, Int J Yoga, vol. 13, no. 2, pp. 160-167, 2020. doi: 10.4103/ijoy.IJOY_39_19.

[57] Telles S, Sharma S, Balkrishna A. "Blood pressure and heart rate variability during yoga-based alternate nostril breathing practice and breath awareness”, Med Sci Monit Basic Res, vol. 19, no.20, pp. 184-193, 2014. doi: 10.12659/MSMBR.892063

[58] Vaschillo E., Fonoberova M., Mezic I., Buckman J., Fonoberov V., Mezic A., Vaschillo B., Bates M. "A Computational Physiology Approach to Personalized Treatment Models: The Beneficial Effects of Slow Breathing on the Human Cardiovascular System”, AJP Heart and Circulatory Physiology, vol. 307, no. 7, pp. 1073-1091, 2014. doi: 10.1152/ajpheart.01011.2013

[59] Noskin L., Rubinskiy A., Romanchuk A. "Indications of the Level Individual Cardiovascular and Respiratory Homeostasis Using Continuous Spiroarteriocardiorhythmography”, Biomed J Sci\&Tech Res, vol.6, no.1, 2018. doi:10.26717/BJSTR.2018.06.0013 09

[60] Noskin L., Rubinskiy A., Marchenko V., Lamden Yu., Pivovarov V., Cherepov A. "Multisystemic differential diagnosis of external respiration and cardiovascular synchronism in patients with different disease profiles", Pathogenesis, vol. 17, no. 3, pp. 65-73, 2019. doi: 10.25557/2310-0435.2019.03.65-73 (in Russ.).

[61] Telles S., Verma S., Sharma S., Gupta R., Balkrishna A. "Alternate-nostril yoga breathing reduced blood pressure while increasing performance in a vigilance test”, Med Sci Monit Basic Res, no. 23, pp. 392-388, 2017. doi: 10.12659/msmbr.906502

[62] Guziy O., Romanchuk A. "Multifunctional determinants of athletes' health", Journal of Medicine and Health Research, vol. 2, no. 1, pp. 2-21, 2017. Retrieved from https://www.ikprress.org/index.php/JOMAHR/article/view/ 3314

[63] Tyagi A., Cohen M. "Yoga and heart rate variability: A comprehensive review of the literature", Int J Yoga, vol. 9, no. 2, pp. 97-113, 2016. doi: 10.4103/0973-6131.183712.

[64] Vaschillo E., Vaschillo B., Pandina R., Bates M. "Resonances in the cardiovascular system caused by rhythmical muscle tension", Psychophysiology, vol. 48, no. 7, pp. 927-36, 2011. doi: 10.1111/j.1469-8986.2010.01156.x

[65] Romanchuk A. "By the assessment of autonomic nervous system activity in athletes", Med rehab res physioth, no. 4, pp. 31-34, 2005. (In Ukr.)

[66] Wesseling K., Karemaker J., Castiglioni P., Toader E., Cividjian A., Settels J., Quintin L., Westerhof B. "Validity and variability of xBRS: instantaneous cardiac baroreflex sensitivity”, Physiol Rep, vol. 5, no. 22, e13509, 2017. doi: 10.14814/phy2.13509

[67] Breslav I., Volkov N., Tambovceva R. "Breathing and muscle activity of man and sport”, Moscow, Sovetskij sport, 2013. (in Russ.).

[68] Pokrovskiy V. “Cardiorespiratory synchronism in assessing the body's regulatory and adaptive capabilities”, Krasnodar, Kuban-kniga, 2010. (in Russ.).

[69] De Souza L., Ferreira J., Schein ASd., Dartora D., Casali A., Scassola C., Tobaldini E., Montano N., Guzzetti S., Porta A., Irigoyen M., Casali K. "Optimization of Vagal Stimulation Protocol Based on Spontaneous Breathing Rate", Front Physiol, no. 9, p. 1341, 2018. doi:10.3389/fphys.2018.0134 1

[70] Pivovarov V. "Information-measuring system for functional diagnostics of nervous regulation of blood circulation. Part II. The implementation”, Automation and remote control, vol. 72, no. 3, pp. 671-676, 2011. doi: 10.1134/S000511791103 0192 